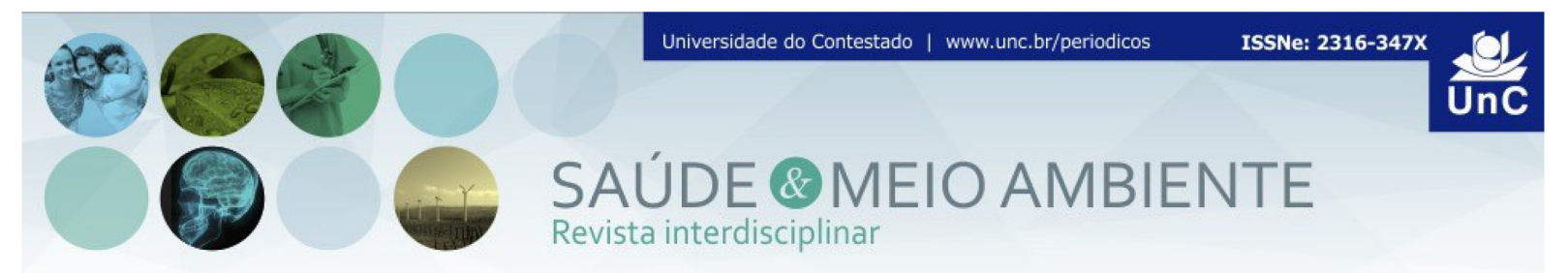

\title{
ESTUDO EXPERIMENTAL IN VIVO E IN VITRO DE PLANTAS MEDICINAIS NOS PROCESSOS DE EMBRIOTOXICIDADE E TERATOGENICIDADE
}

\section{EXPERIMENTAL IN VIVO AND IN VITRO STUDIES OF MEDICINAL PLANTS IN EMBRYOTOXICITY AND TERATOGENICITY PROCESSES}

\author{
Regineide Xavier Santos ${ }^{1}$ \\ lara Pacheco Gomes Volejo ${ }^{2}$
}

\begin{abstract}
RESUMO
Este trabalho tem como objetivo contribuir na compilação de artigos científicos sobre as plantas medicinais que possuem efeitos embriotóxicos e teratogênicos comprovados através de testes experimentais in vivo e in vitro. Foi realizado um levantamento nas bases de dados Medline, Pubmed, Web of Science, Cochrane, Biblioteca virtual em saúde, Lilacs e Scielo com os descritores, "Medicinal plants, embryotoxicity"; "Medicinal plants, Teratogenic effects"; "Medicinal plants, teratogenicity" e seus correspondentes em português: "Plantas medicinais, embriotoxicidade"; "Plantas medicinais, efeitos Teratogênicos"; "Plantas Medicinais Teratogenicidade". Oito artigos de ensaios in vivo e quatro de in vitro e um que apresenta os dois ensaios, preencheram os critérios de inclusão e exclusão e foram selecionados para esta revisão. Destes, cinco foram realizados na América, um na Europa, três na África e dois na Ásia. Na maioria dos estudos in vivo o extrato da planta foi injetado no animal, observando assim seus efeitos. A partir deste estudo, foi verificado que as plantas podem apresentar algum tipo de efeito no processo embrionário, portanto, o consumo durante o estado gravidico deve ser avaliado por um profissional da área.
\end{abstract}

Palavras-chave: Gestação. Planta medicinal. Embriotoxicidade. Teratogênico.

\section{ABSTRACT}

This work aims to contribute to the compilation of scientific articles on medicinal plants that have embryotoxic and teratogenic effects proven through experimental tests in vivo and in vitro. A survey was carried out in the Medline, Pubmed, Web of Science, Cochrane, Virtual Health Library, Lilacs and Scielo databases with the descriptors, "Medicinal plants, embryotoxicity"; "Medicinal plants, Teratogenic effects"; "Medicinal plants, teratogenicity" and their Portuguese counterparts: "Medicinal plants, embryotoxicity"; "Medicinal plants, Teratogenic effects"; "Medicinal Plants

\footnotetext{
1Doutora em Genética e Biologia Molecular pela Universidade Estadual de Santa Cruz. Docente da Universidade Estadual do Sudoeste da Bahia (UESB). Bahia. Brasil. E-mail: regineide.xavier@uesb.edu.br

${ }^{2}$ Graduada em Ciências Biológicas pela Universidade Estadual do Sudoeste da Bahia, UESB. Bahia. Brasil. E-mail: iara.pgomes@hotmail.com
} 
Teratogenicity". Eight articles from in vivo tests and four from in vitro and one that presents both tests, met the inclusion and exclusion criteria and were selected for this review. Of these, five took place in America, one in Europe, three in Africa and two in Asia. In most studies in vivo, the plant extract was injected into the animal, thus observing its effects. From this study, it was found that plants can have some type of effect on the embryonic process, therefore, consumption during pregnancy should be evaluated by a professional in the field.

Keywords: Gestation. Medicinal plant. Embryotoxicity. Teratogenic.

\section{INTRODUÇÃO}

As plantas medicinais são usadas no tratamento terapêutico desde os tempos antigos. Onde, os conhecimentos populares foram transmitidos pelos descendentes tornando se essenciais, pois o conhecimento que parte da cultura perpassou gerações ${ }^{1}$. O desafio de conhecer as potencialidades química e farmacológica, tendo em vista a grande biodiversidade da flora tem aumentado a cada ano.

Atualmente tem se observado, uma relevância quanto ao uso de plantas medicinais e fitoterápicos nos cuidados e atenção à saúde básica ${ }^{2}$. Acredita-se que o aumento de consumo, estejam relacionados ao surgimento de novas enfermidades, a crendice de que o "natural" é sempre benéfico, a percepção de que há superioridade de ação do medicamentos naturais aos sintéticos, pelas dificuldades na utilização dos serviços de saúde, pelo alto valor dos remédios alopáticos ou até mesmo pelos incentivos das politicas governamentais ${ }^{3,4,5,6}$. Outro fator também importante para o aumento do consumo, é a acessibilidade às plantas medicinais, bem como, a obtenção de um remédio mais viável economicamente ${ }^{7}$. Entretanto, Pedroso e Andrade $^{8}$, pontua para uma desatenção muitas vezes ao tema, uma vez que normalmente não há nenhuma orientação por parte dos profissionais de saúde ${ }^{8}$.

As plantas medicinais tem sido de maneira recorrente, considerada como uma terapia de ação supostamente inofensiva à saúde ${ }^{9}$. Todavia, o seu uso indiscriminado e sem orientação correta, pode está susceptível a efeitos adversos, seja pelo uso esporádico ou crônico ${ }^{8}$. Os vegetais são complexos do ponto de vista fitoquímico, possuem substâncias tóxicas produto do mecanismo de defesa próprio, além dos princípios biologicamente ativos ${ }^{10}$. Tais substâncias ou a interação entre elas, podem afetar a gestação de diversas maneiras, como a indução de atividade teratogênica, interrupção da gravidez ou produzir uma malformação fetal. Qualquer período da gestação (implantação, embrionário ou fetal) os componentes orgânicos presentes nos extratos das plantas medicinais podem passar pela barreira placentária e alcançar o embrião ${ }^{11,12}$.

As substâncias teratogênicas pode ter ação no feto, provocar mudanças morfológicas e funcionais, pelas alterações no DNA, quebra dos cromossomos, influência na mitose e deficiências bioquímicas ${ }^{13}$. A exposição materna a substâncias tóxicas, pode interferir nos processos de proliferação celular e promover alterações 
no sistema nervoso central, e causar retardo geral do desenvolvimento do feto ${ }^{14}$. $\mathrm{O}$ abortamento também é passível de ocorrer por fatores, como por exemplo, alterações do balanço hormonal da gestante, aumento na contratilidade uterina ou até mesmo alterações no desenvolvimento do embrião pela presença de substâncias citotóxicas, entre outros ${ }^{15}$.

As informações obtidas sobre as plantas medicinais, se dar pelo conhecimento popular e, pela comunidade científica com suas contribuições e possíveis riscos do uso associados a várias espécies da flora. Dessa maneira, os testes toxicológicos de substâncias é uma etapa importante para se estabelecer a terapêutica de uma planta medicinal. Nos ensaios in vitro são inúmeros os bioensaios utilizados para a avaliação dos efeitos tóxicos das espécies vegetais. Já nos ensaios in vivo, com animais de laboratório são feitos os ensaios de toxicidade aguda e crônica ${ }^{16}$.

Entretanto, neste cenário existe informações controversas sobre os efeitos terapêuticos e toxicológicos sobre as plantas medicinais, assim diante do exposto, o objetivo deste estudo é contribuir na compilação de dados científicos em único documento sobre as plantas medicinais que possuem efeitos embriotóxicos e teratogênicos comprovado através de testes experimentais in vivo e in vitro.

\section{METODOLOGIA}

Foi utilizado o método de revisão bibliográfica integrativa, que teve como finalidade reunir dados científicos da literatura sobre o tema investigado. Esta metodologia possibilitou a análise crítica e a síntese de estudos anteriores além de contribuir para maior compreensão sobre a temática proposta nesta revisão. $O$ processo de elaboração deste estudo foi realizado em seis etapas: (a) definição das questões norteadoras; (b) estabelecimento de critérios para inclusão e exclusão dos estudos; (c) busca na literatura; (d) avaliação dos estudos; (e) interpretação dos resultados e (f) síntese. A pergunta norteadora desta revisão foi: "Na literatura científica, quais plantas medicinais são indicadas com efeitos embriotóxicos e/ou teratogênicos através de testes experimentais in vivo e in vitro?

Para a realização do levantamento bibliográfico, os descritores em inglês (Medicinal plants, embryotoxicity; Medicinal plants, Teratogenic effects; Medicinal plants, teratogenicity) e em português (Plantas Medicinais, Embriotoxicidade; Plantas Medicinais, Efeitos Teratogênicos; Plantas Medicinais, Teratogenicidade) foram definidos após a consulta aos Descritores em Ciências da Saúde (DeCS) realizada no portal da Biblioteca Virtual de Saúde (decs.bvs.br). Diferentes combinações dos descritores selecionados foram combinadas com o operador booleano AND em pesquisas realizadas nas bases de dados PubMed (National Library Medicine), Scielo (Scientific Eletronic Library Online), Web of Science (Science Citation Indexes), Medline (SistemaOnline de Busca e Análise de Literatura Médica), Lilacs (Literatura Latino-americana e do Caribe em Ciências da Saúde) e Biblioteca Virtual em Saúde entre os meses de Abril e Maio de 2019. 
Nas bases de dados foram selecionadas as publicações e após a leitura dos títulos e resumos (abstracts), foram excluídas as duplicatas, as revisões, os estudos não experimentais in vivo e in vitro e as publicações que não estavam relacionadas à temática proposta nesta revisão. Os critérios de inclusão definidos para a seleção dos artigos foram os estudos disponibilizados na íntegra e redigidos nos idiomas inglês, espanhol ou português que informavam ou que permitiam a identificação de plantas com possivel ação teratogênica e/ou embriotóxica analisados por ensaios in vivo e/ou in vitro. Aplicando-se os critérios de inclusão e exclusão foram selecionados os artigos para compor a presente revisão integrativa. A extração e a organização dos dados obtidos nos estudos selecionados foram realizadas adotando-se o método de matriz de síntese, o que levou à categorização dos estudos por continente e a dados sumarizados em tabelas contendo a espécie, nome popular da espécie, tipo de estudo e efeito toxicológico.

\section{RESULTADOS E DISCUSSÃO}

A seleção inicial dos artigos resultou em 113 publicações nas bases de dados pesquisadas. A etapa seguinte foi à aplicação dos critérios de inclusão e exclusão os quais resultaram em 13 artigos. A Figura 1 informa todos os passos seguidos para a viabilização dessa pesquisa e a quantidade de artigos encontrados e selecionados em cada base de dados, em cada etapa da pesquisa.

Figura 1 - Passos para a viabilização da pesquisa e quantidade de artigos encontrados e selecionados em cada base de dados

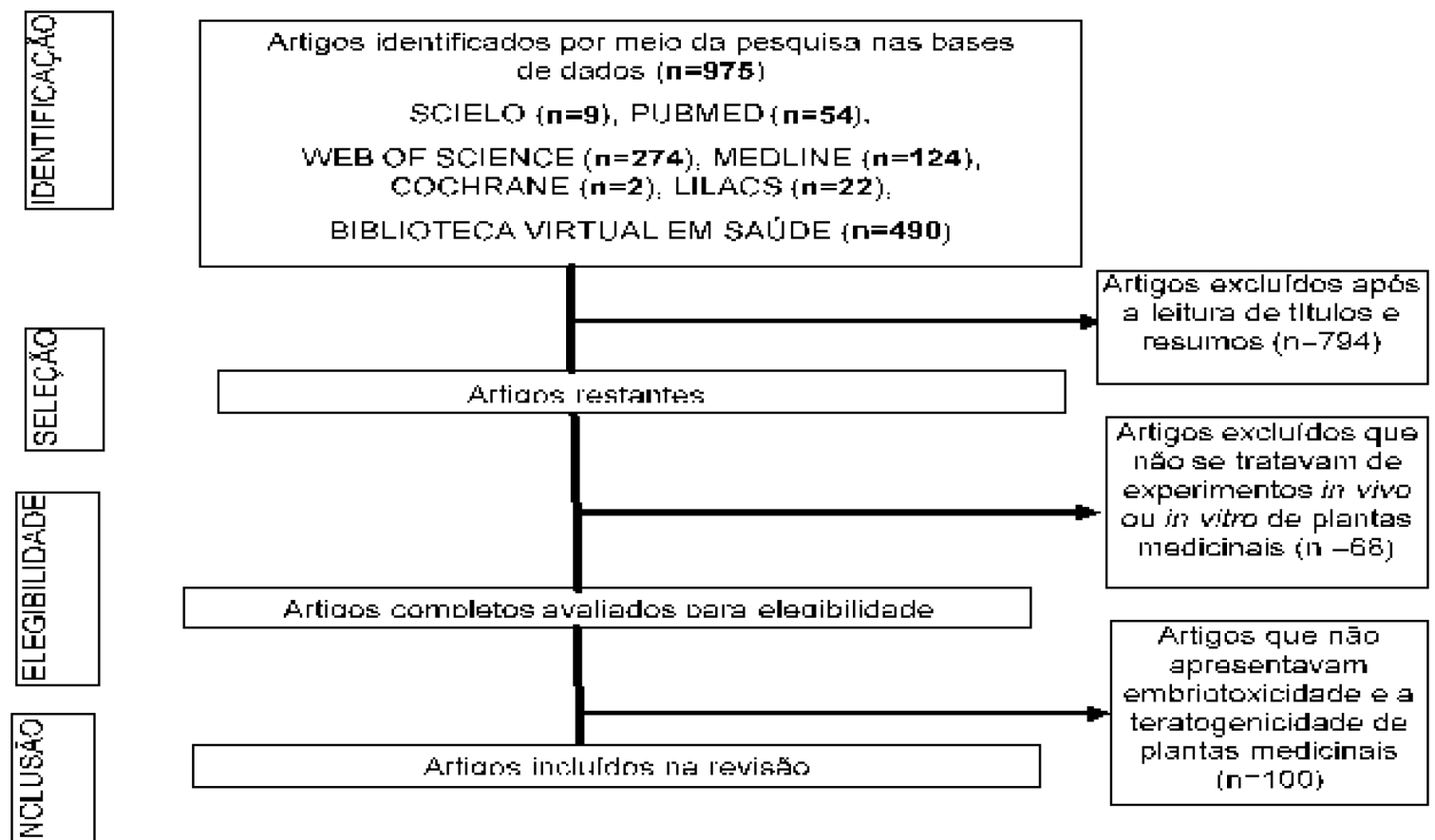

Fonte: Dados da pesquisa 
No Quadro 1 estão listados os artigos relacionados aos estudos experimentais in vivo e in vitro que relatam sobre embriotoxicidade e teratogenicidade de plantas medicinais. Foram selecionados três artigos sobre o efeito embriotóxico, oito sobre o efeito teratogênico dois que retratavam tanto os efeitos teratogênicos quanto embriotóxico das plantas medicinais, sendo considerados as duplicatas (descrições de mutagenicidade e teratogenicidade no mesmo estudo).

Quadro 1 - Estudos com plantas medicinais nos processos de embriotoxicidade e efeitos teratogênicos por ensaios in vivo e in vitro.

\begin{tabular}{|c|c|c|c|}
\hline Referências & Espécies & Efeito toxicológico & Tipo de Estudo \\
\hline $\begin{array}{l}\text { Alafiatayo et al., } \\
2019^{17}\end{array}$ & $\begin{array}{c}\text { Curcuma longa } \\
\text { (Açafrão-da-terra) }\end{array}$ & $\begin{array}{l}\text { Embriotóxico } \\
\text { Teratogênico }\end{array}$ & in vivo \\
\hline Chen et al., $2018^{18}$ & $\begin{array}{c}\text { Sutherlandia } \\
\text { frutescens } \\
\text { (Ervilha-balão) }\end{array}$ & Teratogênico & in vivo \\
\hline $\begin{array}{l}\text { Moraes-Souza et al., } \\
2017^{19}\end{array}$ & $\begin{array}{l}\text { Croton urucurana } \\
\text { (Sangra-d'água, } \\
\text { urucurana) }\end{array}$ & $\begin{array}{l}\text { Embriotóxico } \\
\text { Teratogênico }\end{array}$ & in vivo \\
\hline $\begin{array}{l}\text { Jafarzadeh et al., } \\
2015^{20}\end{array}$ & $\begin{array}{c}\text { Lawsonia Inermis } \\
\text { (Hena) }\end{array}$ & Teratogênico & in vivo \\
\hline $\begin{array}{l}\text { Benavides, D'Arriggo e } \\
\text { Pino, } 2010^{21}\end{array}$ & $\begin{array}{c}\text { Origanum vulgare } L \\
\text { (Orégano) }\end{array}$ & Embriotóxico & in vivo \\
\hline Khalki et al., $2010^{22}$ & $\begin{array}{c}\text { Trigonella foenum- } \\
\text { graecum } \\
\text { (Feno-Grego) }\end{array}$ & Teratogênico & in vivo \\
\hline Yakubu et al., $2010^{23}$ & $\begin{array}{c}\text { Senna alata } \\
\text { (Castiçais do } \\
\text { imperador, arbusto da } \\
\text { vela, mata pasto) }\end{array}$ & Teratogênico & in vivo \\
\hline $\begin{array}{l}\text { Yakubu e Afolayan, } \\
2009^{24}\end{array}$ & $\begin{array}{c}\text { Bulbine natalensis } \\
\text { (N/A) }\end{array}$ & Teratogênico & in vivo \\
\hline $\begin{array}{l}\text { Castañeda et al., } \\
2006^{25}\end{array}$ & $\begin{array}{l}\text { Alchornea } \\
\text { castaneifolia } \\
\text { (Hiporuru) }\end{array}$ & Embriotóxico & in vitro \\
\hline Monteiro et al., $2001^{26}$ & $\begin{array}{c}\text { Vernonia condensata } \\
\text { (Boldo-Baiano) }\end{array}$ & Embriotóxico & in vivo e in vitro \\
\hline $\begin{array}{l}\text { Steenkamp et al., } \\
2001^{27}\end{array}$ & $\begin{array}{l}\text { Senecio latifolius } \\
\text { (Cravo do Campo, } \\
\text { Bem- me-quer) }\end{array}$ & Teratogênico & in vitro \\
\hline Kennelly, et al., $1999^{28}$ & $\begin{array}{l}\text { Caulophyllum } \\
\text { thalictroides } \\
\text { (Cohosh azul) }\end{array}$ & Teratogênico & in vitro \\
\hline Keeler, $1971^{29}$ & $\begin{array}{l}\text { Veratrum californicum } \\
\text { (Falso helébero da } \\
\text { Califórnia) }\end{array}$ & Teratogênico & in vivo \\
\hline
\end{tabular}

Fonte: Dados da pesquisa

As investigações realizadas ocorreram em onze países dos quais se destacam a África do Sul com três publicações. O Brasil aparece em segundo, com duas publicações. Entretanto, esse panorama pode ser considerado pobre, tendo em vista esse total de artigos terem sidos publicados em aproximadamente 50 anos. Haja vista, 
a importância da temática, considera-se que as pesquisas realizadas para avaliação da toxicologia das plantas medicinais para os efeitos no embrião ou feto ainda são incipientes.

Nos países industrializados, cerca de $70 \%$ a $90 \%$ de sua população utilizam as plantas medicinais sobre a medicina complementar, alternativa ou não convencional ${ }^{30}$ e no Brasil, cerca de $80 \%$ da população fazem o uso ${ }^{31}$. Para tanto, os testes toxicológicos quando existentes ainda não são bem planejados para demonstrar que um agente químico presente nas plantas é seguro, mas apenas, se concentra em caracterizar o efeito tóxico que uma substância do vegetal produz ${ }^{32}$.

$\mathrm{Na}$ China, onde a medicina tradicional é baseada em recursos fitoterapêuticos internacionalmente reconhecida ${ }^{33}$ apenas um estudo foi encontrado. Singel e Barros ${ }^{34}$ apresentam a região oriental com o maior número de publicações, quando comparado com o ocidente, todavia, esse dado não se aplica para sobre a mutagenicidade e teratogenicidade de plantas medicinais.

Vale destacar, que o uso muitas vezes irracional e o desconhecimento sobre a existência da toxicidade das plantas e sua utilização pelas gestantes podem levar a sérios danos ao organismo materno, comprometendo a saúde da mãe e do concepto, sendo assim indispensável às pesquisas sobre os riscos que as plantas podem causar $^{35}$.

Analisando os artigos da presente revisão, enfatizado na Tabela 1, podemos verificar que a maioria dos estudos realizados foram ensaios in vivo $(64,28 \%)$, sendo os testes realizados com peixe, rato/camundongo e coelho, e com apenas $(35,72 \%)$ foram feitos estudos experimentais in vitro utilizando sistema vegetal Allium cepa, cepas bacterianas (TA97a, TA98 e TA100), células HuH-7 humanas, cultura de embriões de rato, para avaliar a toxicidade e os possíveis efeitos das plantas in vitro.

Nessa pesquisa foram encontrados treze espécies de plantas descritas com efeito toxicológico embriotóxico, teratogênico e abortiva, sendo elas: Curcuma longa (Açafrão- da-terra), Sutherlandia frutescens (Ervilha-balão), Croton urucurana (Sangra-d'água), Lawsonia inermis (Hena), Origanum vulgare (Orégano), Trigonella foenum-graecum (Feno-grego), Senna alata (Castiçais do imperador), Bulbine natalensis (N/A), Alchomea Castaneifolia (Hiporuru), Vernonia condesata (BoldoBaiano), Senecio latifolius (Cravo do campo), Caulophyllum thalictroides (Cohosh azul) e o Veratrum californicum (Falso helébero da Califórnia).

Alafiatayo et al. ${ }^{17}$, avaliaram a toxicidade do extrato de Curcuma longa (Açafrão-da-terra), sobre o peixe-zebra. Doze embriões fertilizados foram selecionados para testar a embriotoxicidade e teratogenicidade em diferentes pontos de concentração. Foram verificados os efeitos de toxicidade da $C$. longa e observado que a toxicidade era dependente da dose. Em 125,0 $\mu \mathrm{g} / \mathrm{mL}$, houve mortalidade de embriões e as deformidades corporais das larvas foram registradas entre os embriões nascidos em maior concentração do tratamento. O efeito teratogênico do extrato foi severo em concentrações mais altas, produzindo deformidades no corpo físico e aumento do edema do saco vitelino do peixe- zebra. 
No artigo publicado por Chen, et al. ${ }^{18}$, os extratos de Sutherlandia frutescens (Ervilha-balão), foram preparados a partir de dois extratos, um alcoólico (etanol $80 \%$ ) e outro aquoso. Os extratos foram utilizados em concentração de 0 a $200 \mu \mathrm{g} / \mathrm{mL}$ a uma (linha tuebingen) de embrião de peixe-zebra. Ambos os extratos (etanólico e aquoso) levaram à formação de sangramento e a formação de cisto pericárdico quando aplicados em altas concentrações nos embriões do peixe-zebra. As toxicidades teratogênicas crônicas levaram a edemas pericárdicos, edema do saco vitelino e outras características anormais de desenvolvimento. As maiores concentrações dos extratos utilizados nas larvas resultaram em toxicidade letal, enquanto a teratogenicidade foi causada pela exposição dos embriões a concentrações mais baixas. O extrato aquoso de $S$. frutescens foram menos tóxicos nas larvas quando comparados ao extrato etanólico. Esses dados reforçam a preferência por preparações aquosas quando utilizadas na medicina tradicional.

Moraes-Souza et al. ${ }^{19}$, utilizaram ratas, tratadas oralmente por gavagem (método de introdução de alimentos líquidos no estômago através de um tubo colocado pelo nariz ou boca) com extrato de Croton urucurana (Sangra-d'água) ou água durante toda a prenhes para avaliar a toxicidade da planta. $O$ tratamento com $C$. urucurana em concentrações de $400 \mathrm{mg} / \mathrm{kg}$ e tratado dose $800 \mathrm{mg} / \mathrm{kg}$, reduziram o peso corporal fetal e deficiência placentária. O grupo tratado dose $800 \mathrm{mg} / \mathrm{kg}$ apresentaram aumento dos níveis de proteína e colesterol total materno e aumento relativo do coração. Todos os grupos tratados manifestaram redução do peso corporal e ingestão de alimentos, além de aumentarem as taxa de perda pré-implantacional comparado ao grupo controle. Observaram também que o tratamento contribuiu para o aumento das anomalias esqueléticas e viscerais em doses mais concentradas do extrato. $O$ tratamento com $C$. urucurana causou toxicidade materna, o que contribuiu para desenvolvimento fetal embrionário anormal do organismo avaliado.

No estudo experimental com Lawsonia inermis (Hena), Jafarzadeh, et al. ${ }^{20}$, utilizaram camundongos fêmeas (BALB/c). Entre as anormalidades observadas em embriões abortados neste estudo estão as alterações esqueléticas (costela extra, falta de osso parietal, anencefalia e exencefalia). Na concentração de $100 \mathrm{mg} / \mathrm{kg}$ de $L$. inermis, os ossos parietais estavam ausentes em $90 \%$ dos embriões. Os resultados do estudo mostraram que o extrato de $L$. inermis causou redução significativa na altura e peso dos embriões de camundongos. Uma das razões para a ocorrência das anormalidades citadas pelos autores foi à presença de altas quantidades de apigenina, no extrato hidroalcoólicos analisado. Jafarzadeh, et al. ${ }^{20}$, correlaciona a toxicologia obtida a pelo menos em parte, com o componente 2-hidroxi-1,4naftoquinona, tendo em vista, que este componente tem propriedades oxidantes e pode causar hemólise. Esse elemento químico geralmente é metabolizado no fígado e pode se transformar em metabólitos tóxicos e causar uma redução significativa na altura e no peso em estágios críticos de organogênese em embriões de camundongos.

Foi investigado também o efeito do extrato aquoso de Origanum vulgare (Orégano), no desenvolvimento pré-implantacional do embrião de camundongo. O extrato aquoso do orégano foi fornecido a quatro grupos separados $(n=10)$ de camundongos prenhes nas concentrações de 0,9; 18 e $36 \mathrm{mg} / \mathrm{mL}$ respectivamente. Quando os embriões foram avaliados, observou-se um ligeiro atraso no 
desenvolvimento embrionário, mas somente em doses mais altas e um aumento de embriões degenerados em comparação ao grupo controle, devido a um atraso na formação dos blastocistos ${ }^{21}$.

Khalki, et al. ${ }^{22}$, avaliaram os efeitos tóxicos potenciais de sementes de Trigonella foenum-graecum (Feno-Grego), em camundongos prenhes e durante todo o desenvolvimento fetal. Nas fêmeas grávidas, não houve sintomas óbvios de toxicidade, mortes relacionadas com o extrato aquoso liofilizado de sementes de $T$. foenum-graecum ou anormalidades macroscópicas. A toxicidade do desenvolvimento na prole incluiu um aumento na morte fetal, taxa de mortalidade, uma diminuição no tamanho da ninhada e uma redução no peso corporal do feto. Além disso, houve um aumento na incidência de anormalidades morfológicas. Não houve casos de malformação no grupo controle e o número de malformações foi significativamente diferente entre os grupos, sugerindo um efeito provavelmente teratogênico do extrato. Ingestão de extratos da folha no dia $10^{\circ}$ após o acasalamento mostrou uma diminuição do tamanho fetal e um aumento na taxa de mortalidade. Com base nestes resultados, o presente estudo fornece evidências experimentais que o extrato aquoso de sementes de $T$. foenum-graecum afeta a reprodução em camundongos, efeitos tóxicos no desempenho reprodutivo e efeitos potenciais teratogênicos em fetos.

O trabalho de Yakubu, et al. ${ }^{23}$ avaliaram o mecanismo da atividade abortiva do extrato aquoso da folha de Senna alata (Castiçais do imperador), em ratas prenhes. O extrato reduziu significativamente o número dos fetos, peso e taxa de sobrevivência com $250 \mathrm{mg} / \mathrm{kg}$ do extrato, sendo uma indicação da atividade abortiva durante o período pós- implantação. Foi observado também uma redução nos níveis de progesteronas, o que facilita o início do trabalho de parto. Portanto a luteólise e a diminuição dos níveis sanguíneos de progesterona pode contribuir para o antiimplantação e as atividades abortivas. Influência hormonal, alterações no local de implantação, uterogenicidade e alteração no endométrio do útero também pode ser responsáveis pelo mecanismo de ação do extrato como um abortivo.

Para Yakubu e Afolayan ${ }^{24}$ os efeitos da administração oral do extrato aquoso de Bulbine natalensis (N/A), foram avaliados em ratos. O extrato na dose mais alta $100 \mathrm{mg} / \mathrm{kg}$ de peso corporal indica um aumento da falha na taxa de desenvolvimento embrionário, tendo assim um potencial embriotóxico e pode não ser completamente seguro como remédio oral durante a gravidez na dose administrada. O potencial de letalidade embrionária na dose acima mencionada pode não ser mediado por alterações hormonais, mas sim por um efeito sobre o embrião. Sendo assim, prejudicial no desempenho reprodutivo normal dos ratos machos e tendo uma tendência de ser embriotóxico nas ratas fêmeas.

A avaliação dos efeitos citotóxico e embriotóxicos de Alchomea castaneifolia (Hiporuru), foram feitas com extrato metanólico a $10 \%(\mathrm{p} / \mathrm{v})$ em células Allium cepa e em embriões de ouriço-do-mar ${ }^{25}$. Encontraram ação citotóxica suportada pelo atraso acentuado do ciclo celular no $A$. cepa. Na avaliação do efeito embriotóxico de $A$. castaneifolia sobre os embriões do ouriço-do-mar, verificaram um claro atraso no desenvolvimento embrionário, o que ocorreu principalmente pelo bloqueio da passagem do embrião da fase de blástula a gástrula. É importante mencionar que não foi verificado anomalias nos embriões, sendo estes, mesmo, menor do que no grupo 
de controle, indicando que $A$. castaneifolia tem um efeito embriotóxica, mas não teratogênica.

Monteiro et al. ${ }^{26}$, estudaram a Vernonia condensata (Boldo - Baiano), os quais, avaliaram a toxicidade aguda, embriotoxicidade e mutagenicidade de extrato aquoso de folhas de $V$. condensata. Os achados nesse estudo indicam que o extrato não causou mortes nos embriões de camundongos, mas houve uma leve, mas estatisticamente significativa, redução do peso corporal dos fetos, acompanhado de sinais de ossificação tardia em doses mais altas que $2000 \mathrm{mg} / \mathrm{kg}$. Também nessas doses foram vistas alterações esqueléticas, indicando que doses altas de $V$. condensata podem causam um retardo durante o crescimento embrionário no período pré-natal. No entanto, o extrato testado até $5000 \mathrm{mg} /$ placa, não foi mutagênico para as cepas testadoras TA97a, TA98 e TA100.

Steenkamp, et al. ${ }^{27}$, em seu estudo, verificaram o efeito tóxico de Senecio latifolius (Cravo do campo), em células $\mathrm{HuH}-7$ humanas. Em altas doses $(4,5 \mathrm{mg} / \mathrm{L})$ foi observado necrose nas células e em doses menores, destruição do citoesqueleto, fragmentação nuclear e apoptose celular. Doses menores que o equivalente a $330 \mathrm{mg} / \mathrm{mL}$ de retrorsina levaram a células multinucleadas com falha na formação do fuso e aglomeração de cromatina nuclear. Este último achado sugere que o tratamento crônico em baixas doses com remédios tradicionais poderia causar efeitos teratogênicos e/ou carcinogênicos.

No estudo de Kennelly, et al. ${ }^{28}$, para detectar os potenciais teratogênicos do Caulophyllum thalictroides (Cohosh azul), foi usado N-metilcitisina um alcaloide extraido da planta, em cultura de embriões de ratos num ensaio in vitro. Os resultados evidenciaram alta embriotoxicidade, mas ausência de teratogenicidade para os embriões submetidos as concentrações de $5 \mu \mathrm{g} / \mathrm{mL}$ da fração, no entanto, já na dose de $0.5 \mu \mathrm{g} / \mathrm{mL}$ da fração testada se verificou a ação citotóxica em concentrações baixas $(0.5 \mu \mathrm{g} / \mathrm{mL})$.

Para verificar os possiveis efeitos teratogênicos de Veratrum californicum (Falso helébero da Califórnia), Keeler ${ }^{29}$, isolou alcaloides (ciclopamina e jervina) e administrou através de gavagem (método de introdução de alimentos líquidos no estômago através de um tubo colocado pelo nariz ou boca) em coelhos e ovelhas. $O$ pesquisador verificou que em comum com as ovelhas, os fetos dos coelhos, tiveram uma malformação quando sua mãe ingeriu os alcaloides (ciclopamina, 200-300mg/dia e jervina, $250-300 \mathrm{mg} / \mathrm{dia}$ ). Como também, mortes fetais de coelhos, cujas as mães foram alimentadas com veratramina $(75 \mathrm{mg} / \mathrm{dia})$ e veratrina $(15-30 \mathrm{mg} / \mathrm{dia})$ isolados de V. californicum.

As análises obtidas através desta revisão mostram que utilizar determinadas especies de plantas medicinais, podem representar ameaças se consumidas durante o estado gravidico, especialmente para os embriões ${ }^{17}$. Como também, uso indiscriminado de certas plantas deve ser evitado durante a gravidez para prevenir o potencial risco para a saúde materna bem como a sua descendência ${ }^{19}$. 


\section{CONCLUSÃO}

Assim, através desta revisão pudemos perceber que utilizar Curcuma longa (Açafrão-da-terra), Sutherlandia frutescens (Ervilha-balão), Croton urucurana (Sangra-d'água, urucurana), Lawsonia Inermis (Hena), Origanum vulgare L (Orégano), Trigonella foenum-graecum (Feno-Grego), Senna alata (Castiçais do imperador, arbusto da vela, mata pasto), Bulbine natalensis (N/A), Alchornea castaneifolia (Hiporuru), Vernonia condensata (Boldo-Baiano), Senecio latifolius (Cravo do Campo, Bem- me-quer), Caulophyllum thalictroides (Cohosh azul), Veratrum californicum (Falso helébero da Califórnia) durante o período gestacional, podem causar danos na formação do embrião. Diante disso, há importância de mais estudos de cunho científico realizados através de testes experimentais in vivo e in vitro para comprovar de forma mais consistente e recente, os efeitos teratogênico, embriotóxico e abortivos das plantas. Outro fator importante será perpassar as informações acerca da teratogenicidade, embriotoxicidade e abortividade de determinadas especies de plantas para a população, através de projetos e ações que envolvam profissionais de saúde, meio acadêmico e órgãos governamentais. E desse modo, a principal orientação a se passar as gestantes seria a não utilização de planta medicinal sem devida orientação médica. Haja vista, é muito escasso ou muitas vezes contraditórios os estudos a respeito da segurança do uso das plantas medicinais durante a gestação, sendo indispensável análises detalhadas da situação da gestante e da relação risco-benefício para a mãe e o feto.

\section{REFERÊNCIAS}

1 Humenhuk T, Leite DRB, Fritsch M. Conhecimento popular sobre plantas medicinais utilizadas no município de Mafra, SC, Brasil. Saúde e meio ambient.: rev. interdisciplin. 30 mar. 2020; 9: 27-42. Doi: https://doi.org/10.24302/sma.v9i0.2466

2 Castro M R, Figueiredo FF. Estudos e pesquisas sobre o uso de plantas medicinais e fitoterápicas no Brasil: caminhos e desafios. Ar@ cne. 2020; 24. Doi: https://doi.org/10.1344/ara2020.240.30986

3 Fontanella F, Speck FP, Piovezan AP, Kulkamp IC. Conhecimento, acesso e aceitação das práticas integrativas e complementares em saúde por uma comunidade usuária do Sistema Único de Saúde na cidade de Tubarão - SC. Associação Catarinense de Medicina. 2007; 36(2): 69-74.10. Disponível em http://www.acm.org.br/acm/revista/pdf/artigos/484.pdf

4 Zeni ALB, Bosio F. O uso de plantas medicinais em uma comunidade rural de Mata Atlântica - Nova Rússia, SC. Neotropical Biology Conservation. 2011; 6(1): 55-63. Disponível em: https://www.researchgate.net/publication/279725647 O uso de plantas medicin ais em uma comunidade rural de Mata Atlantica - Nova Russia SC 
5 Reis FC. Projeto de implementação do uso adequado da fitoterapia na unidade de saúde de águas férreas do Município de São Pedro dos Ferros, Minas Gerais, Ipatinga- Minas Gerais, 2018. Trabalho de Conclusão de Curso (Especialização em Gestão do Cuidado na Saúde da Família) - Universidade Federal de Minas Gerais. Ipatinga, MG; 2018. Disponível em:

https://www.nescon.medicina.ufmg.br/biblioteca/imagem/FRANKLIN-CRISTIANOREIS.pdf

6 Mendonça RCF, Morais CDB, Feitosa FLS, Coelho JLG, Andrade FSN, Ferreira LM, Sousa LM et al. Use of medicinal plants by pregnant women in a Bacic Health Unit of Juazeiro do Norte - CE . RSD. 2021 Mar. 22;10(3):e47610313202. Doi: https://doi.org/10.33448/rsd-v10i3.13202

7 Ribeiro M. Agrimonia eupatoria L. Atividade farmacológica e interações medicamentosas. Revista de Ciências Agrárias. 2017; 40(spe), 321-330. Doi: https://doi.org/10.19084/RCA16183

8 Pedroso, RS; Andrade, G; Pires, RH. Plantas medicinais: uma abordagem sobre o uso seguro e racional. Physis. 2021; 31(2): e310218. Doi:

https://doi.org/10.1590/S0103-73312021310218

9 Veiga Junior VF, Pinto AC, Maciel MAM. Plantas medicinais: cura segura?. Química Nova. 2005;28 (3): 519-528. Doi: https://doi.org/10.1590/S0100$\underline{40422005000300026}$

10 Rangel M., Bragança F.C.R. Representações de gestantes sobre o uso de plantas medicinais. Rev. bras. plantas med. 2009; 11(1): 100-109. Doi: https://doi.org/10.1590/S1516-05722009000100016.

11 Brasil. Resolução SES n¹757, de 18 de fevereiro de 2002. Contraindica o uso de Plantas Medicinais no Âmbito do Estado do Rio de Janeiro e dá outras providências. Diário Oficial do Estado do Rio de Janeiro, 20 fev. 2002; 27(33, Parte I).Disponivel em: http://www.saude.gov.br/images/pdf/2019/janeiro/14/resolucao-ses-ri-1757-18-22002-contra-indica-plantas-medicinais.pdf

12 Goronski F, Gelain LM, Konzen AC, Bender JG, Diefenthaeler H, Roman SS. Perdas fetais induzidas pelo uso do chá de canela em camundongos. In: Congresso Internacional em Saúde; 8. 2021. Disponível em: https://publicacoeseventos.unijui.edu.br/index.php/conintsau/article/view/19373/18 $\underline{106}$

13 Andrade, A., Pinto, SC., Oliveira, RS. (orgs). Animais de Laboratório: criação e experimentação [online]. Rio de Janeiro: Editora FIOCRUZ; 2002. 
14 Alves, M C. Efeitos do extrato aquoso de Phyllanthus niruri Linn sobre parâmetros neurocomportamentais na prole de ratas tratadas durante a gestação e lactação; 2020. 94 fl. Dissertação (Mestrado em Ciências Naturais e Biotecnologia) Programa de Pós-graduação em Ciências Naturais e Biotecnologia, Centro de Educação e Saúde. Universidade Federal Campina Grande. Cuité, Paraíba; 2020. Disponível em: http://dspace.sti.ufcg.edu.br:8080/xmlui/handle/riufcg/12930

15 Zhu Y, Nern A, Zipursky S L, Frye MA. Peripheral visual circuits functionally segregate motion and phototaxis behaviors in the fly. Current Biology. 2009; 19(7): 613-619. Doi: https://doi.org/10.1016/j.cub.2009.02.053.

16 Oliveira M C B, Cruz C K S, Rocha G M M, Brito M G A, Oliveira G A L Toxicidade e atividade antibacteriana de plantas medicinais utilizadas no tratamento de doenças respiratórias: revisão integrativa. Res., Soc. Dev. 2020; 9(9): e244997169-e244997169. Doi: http://dx.doi.org/10.33448/rsd-v9i9.7169

17 Alafiatayo AA, Lai KS, Syahida A, Mahmood M, Shaharuddin NA. Phytochemical Evaluation, Embryotoxicity, and Teratogenic Effects of Curcuma longa Extract on Zebrafish (Danio rerio). Evidence-based complementary and alternative medicine : eCAM. 2019: 3807207. Doi: https://doi.org/10.1155/2019/3807207

18 Chen L, Xu M, Gong Z, Zonyane S, Xu S, Makunga N P. Comparative cardio and developmental toxicity induced by the popular medicinal extract of Sutherlandia frutescens (L.) R. Br. detected using a zebrafish Tuebingen embryo model. Complementary and alternative medicine China. 2018; 18(1): 273-284. Doi: https://doi.org/10.1186/s12906-018-2303-9.

19 Moraes-Souza R Q, Soares T S, Carmo N O, Damasceno D C, Campos K E, Volpato G T. (2017). Adverse effects of Croton urucurana B. exposure during rat pregnancy. J Ethnopharmacol. 2017; 199: 328-333. Doi: https://doi.org/10.1016/i.jep.2016.10.061

20 Jafarzadeh L, Seifi N, Shahinfard N, Sedighi M, Kheiri S, Shirzad H, RafieianKopaei M. Antioxidant Activity and Teratogenicity Evaluation of Lawsonia Inermis in BALB/c Mice. J Clin Diagn Res. 2015; 9(5), FF01-FF4. Doi: https://doi.org/10.7860/JCDR/2015/12290.5911

21 Benavides V, D'Arrigo G, Pino J. Effects of aqueous extract of Origanum vulgare L. (Lamiaceae) on the preimplantational mouse embryos. Rev. peru biol. [Internet]. 2010 Dec [cited 2020 May 19] ; 17(3): 381-384. Available from: http://dev.scielo.org.pe/scielo.php?script=sci arttext\&pid=S172799332010000300015\&lng=en..

22 Khalki L, M'hamed S B, Bennis M, Chait A, Sokar Z. Evaluation of the developmental toxicity of the aqueous extract from Trigonella foenum-graecum (L.) in mice. J Ethnopharmacol. 2010; 131(2), 321-325. Doi:

https://doi.org/10.1016/j.jep.2010.06.033 
23 Yakubu M T, Adeshina A O, Oladiji A T, Akanji M A, Oloyede O, Jimoh G A, Olatinwo A W O, Afolayan A J. Abortifacient potential of aqueous extract of Senna alata leaves in rats. J reprod contracept. 2010; 21(3): 163-177. Doi: https://doi.org/10.1016/S1001-7844(10)60025-9.

24 Yakubu M T, Afolayan A J. Reproductive toxicologic evaluations of Bulbine natalensis Baker stem extract in albino rats. Theriogenology. 2009; 72(3): 322332. Doi: https://doi.org/10.1016/j.theriogenology.2009.01.026

25 Castañeda B C, Mata R C, Mejía R M, Anaya M P, Vásquez L I. Avaliação da ação citotóxica e embriotóxica do extrato metanólico de Alchornea castaneifolia "HIPORURO". Horiz Méd. 2006; 6 (1), 2006. Disponível em: https://pesquisa.bvsalud.org/portal/resource/pt/lil-677721

26 Monteiro MH, Gomes-Carneiro MR, Felzenszwalb I, Chahoud I, Paumgartten FJ. Toxicological evaluation of a tea from leaves of Vernonia condensata. $\mathrm{J}$ Ethnopharmacol. 2001;74(2):149-157. Doi: https://doi.org/10.1016/s03788741(00)00363-9

27 Steenkamp V, Stewart MJ, van der Merwe S, Zuckerman M, Crowther NJ. The effect of Senecio latifolius a plant used as a South African traditional medicine, on a human hepatoma cell line. J Ethnopharmacol. 2001;78(1):51-58. Doi: https://doi.org/10.1016/s0378-8741(01)00321-x

28 Kennelly EJ, Flynn TJ, Mazzola EP, et al. Detecting potential teratogenic alkaloids from blue cohosh rhizomes using an in vitro rat embryo culture. J Nat Prod. 1999;62(10):1385-1389. Doi: https://doi.org/10.1021/np9901581

29 Keeler RF. Teratogenic compounds of Veratrum californicum (Durand). XI. Gestational chronology and compound specificity in rabbits. Proc Soc Exp Biol Med. 1971;136(4):1174-1179. Doi: https://doi.org/10.3181/00379727-136-35453

30 Robinson M M, Zhang X. The world medicines situation 2011: traditional medicines: global situation, issues and challenges. ( $3^{a}$ Ed.) Geneva. World Health Organization; 2011.

31 Rodrigues A G, Simoni C. Plantas medicinais no contexto de políticas públicas. Informe Agropecuário. 2010; 31(255): 7-12.

32 Santos J S, Almeida C C O F. Das plantas medicinais à fitoterapia: uma ciência em expansão. ( $1^{\mathrm{a} e d}$.) Brasília: Editora IFB; 2016. Disponível em: http://revistaeixo.ifb.edu.br/index.php/editoraifb/article/view/369

33 Tang L, Lee AH, Binns CW, Hui YV, Yau KKW. Consumption of Chinese herbal medicines during pregnancy and postpartum: A prospective cohort study in China. Midwifery. 2016;34:205-210. Doi: https://doi.org/10.1016/j.midw.2015.11.010

34 Siegel P, Barros N F. Origens, influências e aplicações das medicinas asiáticas no mundo globalizado. Physis. 2009;19 (2): 553-557. Doi: https://doi.org/10.1590/S0103-73312009000200018. 
35 Silva R, Santana A, Santos A, Cerqueira G. Plantas medicinais utilizadas na saúde da mulher: riscos na gravidez. Diálogos \& Ciência. 2012; 32(2): 243-246. Doi: https://doi.org/10.7447/DC.2012.030

Artigo recebido em: 08/04/2020

Artigo aprovado em: 08/10/2021

Artigo publicado em: 19/10/2021 